\title{
A sala de aula como campo de pesquisa: aproximações e a utilização de equipamentos digitais
}

Oldimar Cardoso

Sonia Teresinha de Sousa Penin

Universidade de São Paulo

\section{Resumo}

Este artigo apresenta considerações de ordem metodológica sobre pesquisas de observação de sala de aula realizadas na cidade de São Paulo, em 2002 e 2005, e em duas cidades francesas, no ano letivo 2006-2007. Com base na metodologia utilizada nessas pesquisas e no diálogo com a bibliografia sobre pesquisas de campo, inclusive de outras áreas, os autores analisam as dificuldades enfrentadas nesse contexto e propõem a utilização de equipamentos digitais em campo como contribuição ao rigor e à validade desse tipo de pesquisa. Na primeira parte do artigo, são discutidos problemas fundamentais da pesquisa de observação de sala de aula, como o estranhamento do familiar, a conquista da "solidariedade" e da "camaradagem" dos atores de campo e o estabelecimento de certa diferença entre observação e interpretação. $\mathrm{Na}$ segunda parte, são apresentados equipamentos digitais utilizados nas pesquisas citadas que não apenas agilizam ou facilitam o ofício do pesquisador. 0 uso desses equipamentos, orientado por uma metodologia que lhes dê sentido, pode auxiliar os pesquisadores de sala de aula a ampliar significativamente o rigor e a validade de seu trabalho ao multiplicar as possibilidades de criação de tipos de fonte de dados. Nessa parte do artigo, é discutido o uso de palmtops, gravadores de áudio e câmeras fotográficas digitais, smartphones, microcâmeras sem fio, notebooks e editores de áudio e vídeo em pesquisas de observação de sala de aula.

\section{Palavras-chave}

Metodologia de observação de sala de aula - Observação participante interpretativa - Representações.
Correspondência:

Oldimar Cardoso

Rua Afonso José de Carvalho, 196

05451-000 - São Paulo - SP

e-mail: oldimar@gmail.com 


\section{The classroom as a research field: approximations and the use of digital equipment}

Oldimar Cardoso

Sonia Teresinha de Sousa Penin

Universidade de São Paulo

Contact:

Oldimar Cardoso

Rua Afonso José de Carvalho, 196

05451-000 - São Paulo - SP

e-mail: oldimar@gmail.com

\begin{abstract}
This article offers considerations of a methodological order about classroom observation studies carried out in 2002 and 2005 in the city of São Paulo and in the 2006/2007 academic year in two French cities. Based on the methodology employed in these studies, and on a dialogue with the literature on fieldworks, including those from other areas, the authors analyze the difficulties faced within this context and propose the use of digital equipment in the field as a contribution to the rigor and validity of this kind of research. In the first part of the article, fundamental problems of the research involving classroom observation are discussed, such as the perplexity with the familiar, the conquest of the "solidarity" and "camaraderie" of the field agents, and the establishment of a difference between observation and interpretation. The second part of the text describes digital equipment used in the above-mentioned studies which do more than just speed up or facilitate the task of the researcher. The use of these equipments, guided by a methodology that gives them meaning, can help researchers in the classrooms to expand significantly the rigor and validity of their work by multiplying the possibilities of creating types of data sources. This part of the article discusses the use of palmtops, audio recorders and digital cameras, smartphones, wireless micro-cameras, notebooks, and audio and video editors in researches involving classroom observation.
\end{abstract}

\section{Keywords}

Classroom observation methodology - Interpretive participative observation - Representations 
A busca de uma melhor explicação para os fenômenos educacionais orienta-se por diferentes perspectivas teóricas e diversas abordagens metodológicas de pesquisa. Ainda que as definições metodológicas se relacionem de forma estreita com a perspectiva teórica adotada por um pesquisador, é possível discutir a respeito dos espaços e dos modos de investigação no interior de um tipo de pesquisa. Situando-se no âmbito da categoria de pesquisa social denominada estudo de campo e mais especificamente referindo-se a estudos de caso, pretende-se neste texto discorrer a respeito de abordagens, métodos e de equipamentos promissores ao alcance e ao desvelamento de fenômenos educacionais específicos que ocorrem nas escolas, no espaço das salas de aula.

\section{Aproximações ao campo de estudo e ao caráter da observação}

No início do século $X X$, os primeiros cientistas sociais foram a campo com o objetivo de ultrapassar a descrição daquilo que Bronislaw Malinowski (1984) chamava de "esqueleto" de uma cultura. Eles passaram a preocupar-se também com a "vida cotidiana" e com o "comportamento habitual", que seriam, por assim dizer, a "carne" e o "sangue" dessa mesma cultura (p. 32).

As metodologias de pesquisa de campo criadas a partir de então visam superar a reificação do social promovida pelas perspectivas que generalizam fatos encontrados somente nas fontes privilegiadas pelo pesquisador. Ao estudar casos específicos no cotidiano, as pesquisas de campo procuram desfazer o mito de uma homogeneidade social passivel de descrição por um número restrito de categorias. Por outro lado, ao negar esses princípios generalizantes, as pesquisas de campo passam a correr o risco ainda mais sério de "sacralização do indivíduo", podendo resvalar num "individualismo metodológico" que, de acordo com Claudia Fonseca (1999), leva à máxima "cada caso é um caso" (p. 59).
As conclusões a que as pesquisas de campo pretendem chegar não se referem a todos os "casos" existentes na realidade, mas também não se restringem apenas ao "caso" observado. Essas pesquisas enfocam um número restrito de contextos para descrever características que possivelmente se apresentam em uma quantidade significativa de outros contextos. Cabe ao pesquisador diferenciar as idiossincrasias observadas nos atores de campo de suas características possivelmente existentes entre os atores de vários outros contextos.

0 que define o rigor de uma pesquisa de campo não é a quantidade de atores observados ou a quantidade de dados criados sobre eles, mas a variedade de tipos de fonte de dados e as possibilidades de comparação entre eles. As pesquisas de campo criam suas próprias fontes de dados, não recorrendo àquelas criadas por terceiros, como séries documentais e estatísticas. Faz-se necessário, então, elaborar uma quantidade significativa de tipos de fonte de dados para que o pesquisador de campo possa criar os dados amparado em fontes de naturezas distintas.

A observação de sala de aula, como um tipo específico de pesquisa de campo, também exige a elaboração de uma quantidade significativa de tipos de fonte de dados. Este artigo propõe que a utilização de equipamentos digitais em campo contribui profundamente com isso e apresenta considerações elaboradas com base na utilização desses equipamentos em pesquisas de observação de sala de aula realizadas pelos autores na cidade de São Paulo, em 2002 e 2005, e em duas cidades francesas, no ano letivo 20062007. Este artigo está focado no conceito de observação participante interpretativa proposto por Frederick Erickson (1985) e no contexto dessas três experiências de pesquisa, optando-se por não polemizar o tema. lsso, porém, não impede que se beneficiem deste relato os pesquisadores que utilizam outras metodologias para observação de sala de aula.

Antes de tratar especificamente do uso de equipamentos digitais na observação de sala de aula, é necessário analisar as características 
mais básicas desse tipo de pesquisa. Uma primeira característica das pesquisas de observação de sala de aula é sua contribuição para superar o que ficou conhecido como "antropologia de varanda” em referência aos etnógrafos que coletavam informações dos nativos nas varandas das casas dos governantes coloniais'. Apesar de deixar seus gabinetes para ir a campo, o que já representa uma mudança significativa para a antropologia, os antropólogos de varanda apenas entrevistam os que se dirigem até eles. Já os observadores de sala de aula não se dirigem até a escola apenas para entrevistar professores e alunos, mas para conviver e experienciar com eles os diferentes espaços e ambientes de ensino e de aprendizagem escolar. Os conceitos de experiência - Erfahrung e vivência - Erlebnis - são utilizados aqui conforme a tradição da filosofia alemã, que define a experiência como o começo de todo o conhecimento e a vivência como a mera passagem do tempo num dado lugar. 0 substantivo Erfahrung é constituído pelo verbo fahren viajar -, que lhe dá o sentido de "partir em viagem para explorar ou ficar a conhecer algo" (lnwood, 1997, p. 130). Por isso, um professor com quarenta anos de "experiência profissional" - no sentido vulgar dessa expressão -, tem quarenta anos de vivência, mas pode não ter qualquer experiência - Erfahrung. A presença do pesquisador em sala de aula também não tem garantias de ser sempre uma experiência. Um pesquisador pode ter uma vivência de um ano em campo sem mesmo um dia de experiência. 0 que faz da presença na cultura escolar uma experiência é a possibilidade de interlocução e reflexão sobre essa cultura. Nesse caso, o pesquisador se constitui como quem partiu para explorar e o professor como quem ficou para conhecer.

Ainda que as pesquisas de observação de sala de aula possam beneficiar-se das reflexões dos antropólogos sobre sua atuação em campo, elas nem sempre se focam nas comparações com elementos externos à sua própria cultura - o que é uma prática corrente na pesquisa antropológica ${ }^{2}$. Diferentemente desse tipo de pesquisa, a de observação de sala de aula não representa uma "ponte entre dois mundos culturais" ${ }^{3}$.

A pesquisa de observação de sala de aula também não precisa ter compromissos rígidos com alguns conceitos e métodos que são canônicos para a antropologia. Por exemplo, o estranhamento do familiar, que é fundamental para a pesquisa antropológica, não é necessariamente uma condição de êxito da pesquisa de observação de sala de aula. 0 problema do estranhamento existe para os antropólogos desde que estes deixaram de se dedicar exclusivamente às culturas que lhes parecem exóticas e passaram a observar também as culturas urbanas nas quais eles próprios estão inseridos. Essa mudança paradigmática exigiu deles um esforço de estranhamento, necessário para não criar uma descrição redundante de sua própria cultura. 0 problema do estranhamento transferiu-se posteriormente para a etnografia da escolarização, pois como seu pesquisador já foi aluno e muitas vezes também já foi ou ainda é professor, tudo que ele observa na sala de aula pode lhe parecer extremamente familiar. Ainda que o estranhamento possa ser um processo importante para a pesquisa de observação de sala de aula - tanto quanto seu inverso, a empatia com o estranho -, o estudo da cultura escolar pode descrever situações familiares sem obrigatoriamente estranhá-las. A descrição do familiar pode ser realizada de forma suficiente se o olhar do pesquisador estiver amparado em uma teorização, com conceitos e categorias de análise consistentes, permitindo uma melhor compreensão desse familiar.

0 estranhamento não se apresenta necessariamente como uma condição de êxito de pesquisas de observação de sala de aula porque

1. Para uma referência à antropologia "de varanda" - on the verandah -, ver Stocking, 1983

2. 0 estabelecimento de paralelos entre culturas distintas, prática comum entre os antropólogos, tem um de seus exemplos clássicos na relação sugerida por Clifford Geertz entre a briga de galos balinesa e a arte europeia. Para essa relação, ver GEERTZ, 1978, p. 318. Para críticas a essa relação, ver Schneider, 1993; Freitas; Batitucci, 1997.

3. Sobre a definição da "ficção antropológica" como uma "ponte entre dois mundos culturais", ver Caldeira, 1988. 
as diferentes experiências e vivências profissionais do pesquisador na área da Educação não são obstáculos à análise do contexto de campo. Inversamente, o confronto das experiências e vivências do pesquisador com as do contexto de campo pode ser um elemento positivo para observações mais argutas a respeito da sala de aula. Essas experiências e vivências não são uma parte da subjetividade do pesquisador que precisaria ser subtraída. Em vez de eliminá-la, o pesquisador precisa dela para adquirir consciência e eventualmente explicitá-la aos atores de campo com o intuito de administrá-la.

0 processo de explicitação das experiências e vivências do pesquisador cumpre ainda, na pesquisa de observação de sala de aula, papel semelhante ao que tem nas pesquisas antropológicas a criação de laços com os atores de campo. De acordo com Clifford Geertz (1978), a conquista da "solidariedade" e da "camaradagem" dos atores de campo torna-se necessária porque o pesquisador é um "invasor profissional”. Por isso, ele precisa conquistar a confiança dos atores de campo para garantir que sua convivência no contexto seja a mais significativa possível. Ele relata como, em uma de suas pesquisas, a criação desses laços dependeu de um episódio inesperado: a invasão pela polícia da aldeia em que ele pesquisava. De acordo com esse autor, o fato de ele também fugir da polícia durante esse episódio, mesmo sem precisar, garantiu a aproximação necessária em relação aos atores de campo pesquisados, mudando sua relação com eles e interferindo positivamente nos resultados da pesquisa.

Outro autor que refletiu sobre a necessidade da criação de laços com os atores de campo foi William Foote-White (1980). Confundido inicialmente pelos atores de campo de sua pesquisa com um investigador da polícia federal, precisou agir rapidamente para adquirir sua confiança. 0 autor percebeu que valiam mais as "relações pessoais que desenvolvesse do que as explicações que pudesse dar" (p. 79). Ele notou que, para os atores de campo de sua pesquisa - moradores de um bairro de migrantes italianos em Chicago -, ele escrevia um livro sobre o seu bairro. Para esse autor, isso era extremamente vago e exigia maiores explicações. Todavia, para os atores de campo, essa explicação já era suficiente, e poderia significar algo bom ou ruim, dependendo apenas da opinião que tivessem sobre sua pessoa. FooteWhite (1980) também percebeu nessa pesquisa que atores de campo não esperavam que ele fosse um igual, inclusive rejeitando suas tentativas equivocadas nesse sentido. A expectativa dos atores de campo era apenas de uma integração com o pesquisador, mas não de uma "integração completa" com ele.

Um observador de sala de aula não pode depender de um episódio inesperado, como o que ocorreu com Geertz (1978), para o estabelecimento de relações pessoais sem a pretensão de se tornar um igual, como sugere Foote-White (1980). Um dos cuidados que um observador de sala de aula pode tomar para estabelecer relações pessoais com os atores de campo é a aproximação direta com os professores, para evitar que a presença do pesquisador pareça alguma imposição da direção da escola ou de outra instância burocrática hierarquicamente superior. Se o pesquisador não tomar esse cuidado, os atores de campo podem se esquivar dele ou até proibilo de observar suas aulas (Cardoso, 2003).

Além desse cuidado inicial, é importante que o pesquisador procure todo o tempo compartilhar suas experiências com os atores de campo, tanto para ajudá-los a solucionar problemas cotidianos quanto para, pelo menos, esboçar um sentido aos problemas insolúveis. 0 pesquisador também pode compartilhar suas vivências com os atores de campo, para ser visto como igualmente submetido aos problemas da cotidianidade ${ }^{4}$. Numa pesquisa realizada na França, uma professora recebeu com ressalvas um dos autores deste artigo, dizendo aos alunos no momento de sua apresentação: “- Nós somos um pouco suas cobaias”. No entanto, essa professora tornou-se menos incomodada

4. Para o conceito de cotidianidade, ver Penin, 1989. 
com a presença do pesquisador assim que soube que ele era professor da mesma disciplina. A identidade profissional com os atores de campo facilita o mimetismo do pesquisador e a obtenção da solidariedade e da camaradagem necessárias à sua pesquisa. 0 momento-chave para a aceitação da presença do pesquisador pela professora citada foi o diálogo que se estabeleceu entre eles sobre a inspeção que ela sofreria na semana seguinte. Os professores franceses são subordinados a um inspecteur de sua disciplina, que assiste a suas aulas e lhes atribui notas com impacto sobre sua progressão na carreira e sobre seus salários. Essa professora estava iniciando o segundo ano da carreira no momento da pesquisa e foi então inspecionada pela primeira vez. A aceitação do pesquisador por parte da professora parece ter aumentado depois que esse compartilhou com ela dicas sobre a inspeção - coletadas com outros professores franceses - e ofereceu-lhe um livro que poderia ajudá-la a preparar a aula da inspeção. Ao demonstrar-se solidário aos problemas cotidianos dos professores, o pesquisador pôde garantir a aceitação necessária à sua pesquisa.

Se a solidariedade e a camaradagem são condições essenciais para a realização de uma pesquisa de observação de sala de aula, elas não precisam levar o pesquisador a reproduzir o discurso dos atores de campo. Uma pesquisa de observação de sala de aula não precisa ter a pretensão documentadora de resgatar ou de preservar para a posteridade as falas dos professores. Ela também não precisa ter "aspirações democráticas” de incluir objetos tradicionalmente desprezados pela pesquisa social ${ }^{5}$. Uma pesquisa de observação de sala de aula não precisa contemplar essas duas aspirações porque não tem o poder de apresentar objetivamente os pensamentos, as falas ou outras ações dos atores de campo. 0 que a pesquisa de campo apresenta são dados construídos pelo pesquisador. Todas as informações obtidas pelo pesquisador em campo são fontes e não dados. Os dados são construídos com base nessas informações por um meio formal de análise
(Erickson, 1985). A pesquisa de campo apresenta as interpretações do pesquisador sobre as representações dos atores de campo. Descrever as representações de atores de campo é mais do que registrar o que eles dizem ou fazem: é buscar compreender suas palavras e suas outras práticas sociais também por meio de suas ausências - por meio da compreensão de por que eles não fazem uma parte do que dizem, por que eles jamais falam sobre uma parte do que fazem e por que eles não falam ou não agem sobre alguns dos aspectos do trabalho de sua área de atuação ${ }^{6}$.

Uma pesquisa de observação de sala de aula pode buscar uma relação de empatia com os atores de campo, analisando suas representações a partir da compreensão de seus pontos de vista. Para isso, é necessário estabelecer uma certa diferença entre observação e interpretação ${ }^{7}$. É necessário dizer "uma certa diferença”, pois observação e interpretação são parte de um mesmo processo ${ }^{8}$. Observamos o mundo por meio de sentidos culturalmente enformados, impossibilitados de isenção. Procurar distinguir observação de interpretação não significa a crença na objetividade científica absoluta. Isso significa a busca constante da maior proximidade possível com o objeto, mesmo sabendo que, por definição, ele nunca será alcançado. Para Karel Kosik (apud Penin, 1980), a "totalidade não significa todos os fatos" (p. 29) e acumulá-los não implica conhecer a realidade. Os fatos são conhecimento de realidade somente se compreendidos como partes de um todo. Nesse sentido, a totalidade não significa tudo, mas as articulações essenciais que ligam o objeto de estudo a eventos específicos.

Aqui não está em discussão o fato de a pesquisa de observação de sala de aula represen-

5. Sobre a ideia de democratização dos objetos da pesquisa social, ver Thomson, 1996

6. Sobre os conceitos de "representação", "palavras", "prática social" e "ausência", ver Lefebvre, 1983; e Penin, 1989; 1994; 1995.

7. Para um exemplo de pesquisa que diferencia observação de interpretação, ver Willis, 1991.

8. Norwood Russell Hanson (1975) considera que as "observações e interpretações são inseparáveis - não apenas no sentido de que nunca se manifestam separadamente, mas no sentido de que é inconcebível manifestar-se qualquer das partes sem a outra" (p. 127). 
tar uma ciência dura - hard science - ou uma ciência mole - soft science -, já que os pesquisadores de qualquer disciplina utilizam olhos, cérebro e linguagem para observar o mundo. Tanto uma ciência humana - Geisteswissenschaft quanto uma ciência social - Sozialwissenschaft ou uma ciência da natureza - Naturwissenschaft - nunca atingem a objetividade científica absoluta. Ainda assim, dado seu status institucional, a pesquisa de observação de sala de aula tem a responsabilidade de estabelecer como meta a máxima aproximação em relação ao objeto para não resvalar num ficcionismo incompatível com suas funções no interior de uma universidade pública.

Buscar distinguir observação de interpretação significa realizar uma observação mais refletida do que espontânea, focada também nos gestos, não somente nos sentidos atribuídos a eles. Para um exemplo concreto, a tentativa de separar observação de interpretação ocorre quando o pesquisador registra em campo que o professor chegou atrasado 10 minutos e 30 segundos e não que ele chegou muito atrasado. 0 mesmo ocorre quando se registra o número de alunos fora da carteira e o que exatamente esses alunos faziam, em vez de registrar que a sala estava desorganizada. Ou ainda, essa tentativa de separar observação de interpretação ocorre quando se registra que um professor de História afirmou que os populistas eram "demagogos" - e se pergunta ao final da aula para o professor o que exatamente essa palavra significa para ele naquele contexto -, em vez de registrar que o professor criticou o populismo.

0 objetivo dessa tentativa de separação entre observação e interpretação é garantir que a retomada do material elaborado e coletado pelo pesquisador em campo permita atribuir aos gestos um sentido diferente daquele que seria atribuído no calor do campo. Se o pesquisador registra que o professor chegou muito atrasado, que a sala estava desorganizada ou que o professor criticou o populismo, não há a oportunidade de reinterpretar esses gestos de uma forma mais refletida. Em suma, buscar separar observação de interpretação significa evitar juízos de valor muito rígidos em campo para permitir um papel importante à reflexão efetuada fora dele. Em outros casos, mais complexos do que os expressos nesses exemplos, essa separação é impossível. Então, observação e interpretação fundem-se em campo de forma indistinguivel. Por isso, essas tentativas de separar observação de interpretação não garantem nenhuma objetividade à interpretação do pesquisador, mas expressam sua responsabilidade de aproximar-se constantemente de seu objeto. Essa responsabilidade é necessária para evitar que a pesquisa de observação de sala de aula fique refém da autoridade do pesquisador e para permitir que essa pesquisa assuma como critérios de validade a apresentação de "provas" e a adequação de suas afirmações ao real ${ }^{9}$.

A pesquisa de observação de sala de aula gera uma interpretação não totalizante da cultura escolar ${ }^{10}$. Essa pesquisa não interpreta as representações dos atores de campo, mas representações de atores de campo. Por isso, ela se restringe a observar intensamente um pequeno número de professores ou alunos. Os resultados de uma pesquisa de observação de sala de aula não dizem respeito a todos os professores e alunos, mas identifica fenômenos que não se encerram sobre os poucos atores observados na pesquisa. Enfim, ela identifica novos fenômenos, mas não busca determinar a sua grandeza.

\section{Observação e coleta de dados em sala de aula: a utilização de equipamentos digitais}

Quando os primeiros cientistas sociais foram a campo, contavam apenas com lápis, blocos de papel e máquinas de escrever para criar suas fontes de dados. Hoje, as máquinas de escrever podem ser substituídas por computa-

9. Como escreveu Paul Willis (1991), as "teorias devem ser julgadas, em última instância, pela adequação que representam em relação à compreensão do fenômeno que elas pretendem explicar - não em relação a si mesmas" (p. 236). Sobre o conceito de "prova", ver GINZBURG, 2002.

10. Sobre o conceito de cultura escolar, ver Chervel, 1990; 1998. 
dores pessoais e notebooks; os blocos de notas por palmtops; e as câmeras fotográficas e gravadores de áudio, surgidos posteriormente, por câmeras de vídeo portáteis ou microcâmeras. Esses aparelhos digitais poderiam ser entendidos como mera modernização de seus antepassados mecânicos. No entanto, o que se propõe aqui é que o uso de equipamentos digitais na pesquisa de campo não apenas agiliza ou facilita o ofício do pesquisador. 0 uso desses equipamentos, desde que orientado por uma metodologia que lhes dê sentido, pode auxiliar os pesquisadores a ampliar significativamente o rigor e a validade de seu trabalho ao multiplicar as possibilidades de criação de tipos de fonte de dados.

\section{Elaboração de notas de campo digitais}

A elaboração de notas de campo em formato digital foi o recurso mais comum proporcionado pelo uso desses equipamentos. Tal formato garantiu um processo sistemático de recuperação e regulação das notas durante o trabalho de campo e viabilizou sua comparação instantânea e posterior com as conclusões de outras pesquisas.

Segundo Roger Sanjek (1990), o tipo mais comum de nota de campo é o "apontamento" ou scratch note. Os apontamentos são produzidos diante dos atores de campo, enquanto são observados ou se conversa com eles. Normalmente, os apontamentos são escritos de forma abreviada e mnemônica em pequenos blocos de notas. Entretanto, quando elaborados num palmtop, diversos problemas metodológicos existentes em torno deles podem ser solucionados como ocorreu nas pesquisas anunciadas.

A falta de agilidade nas anotações foi o primeiro problema minimizado pelo uso de um palmtop. Esse equipamento permitiu que as aulas fossem registradas com facilidade mesmo caminhando pela sala. Um caderno de notas ou mesmo um notebook dificultam as anotações do pesquisador, quando, por exemplo, ele tem de acompanhar o professor no atendimento con- secutivo a diferentes grupos de alunos pela sala de aula. Além disso, a luz de fundo de tela permite ao pesquisador realizar anotações mesmo no escuro, quando os alunos estão assistindo a vídeos.

0 segundo problema relativo aos apontamentos que um palmtop ajudou a solucionar foi a observação pelos alunos daquilo que se anotava. Como sua tela reflete a luz em várias direções, somente quem o está utilizando pode visualizar o que está sendo escrito e os alunos à volta do pesquisador têm sempre grande dificuldade para enxergar o que ele escreve. Isso garante que as observações do pesquisador sobre a aula não sejam vistas pelos alunos. É claro que em alguns momentos as observações do pesquisador podem ser compartilhadas com professores e alunos. Todavia, é importante que tal instrumento de pesquisa garanta o conhecimento das notas de campo apenas quando isso for do interesse do pesquisador.

A elaboração de apontamentos e notas de campo em formato digital auxilia o pesquisador a evitar a tipificação prematura dos acontecimentos observados, indicada por Frederick Erickson (1985) como uma das ameaças ao rigor de uma observação participante interpretativa. Quando os apontamentos e as notas de campo são elaborados em papel, fica praticamente impossível resgatar as informações neles contidas depois de meses de pesquisa. Nesse caso, a única função do apontamento é servir de base para a elaboração das notas de campo. Isso ainda exige a criação de um índice que permita recuperar o grande volume de informações resultante da presença em campo por um longo prazo.

Com a elaboração de notas de campo em formato digital, todas as informações podem ser resgatadas a qualquer momento por meio de uma ferramenta de busca. Basta digitar qualquer palavra nessa ferramenta para que ela localize todos os trechos de anotações de aula que a contém, o que desobriga a criação de um índice. Sem ter de elaborar um índice, o pesquisador evita a tendência a tirar conclusões indutivamente desde as etapas iniciais do pro- 
cesso de pesquisa. Com a ferramenta de busca, não há o risco de se perder uma informação, considerada irrelevante no início da pesquisa e importante mais adiante, pelo fato de ela não fazer parte do índice.

No palmtop, os apontamentos precisam ser realizados sempre na ordem cronológica dos acontecimentos, que é a forma mais rápida. Qualquer outro critério de anotação envolve a procura do local certo para dispor a informação, o que desvia demais a atenção do pesquisador daquilo que ele precisa observar. Para facilitar a organização dos apontamentos, é relevante que seja criado no palmtop um novo arquivo de texto para cada turma por dia, que receba como nome a data, a turma e o professor observados. No início dos arquivos que registram aulas também gravadas em vídeo, podem ser anotados os tempos de início e fim da gravação para facilitar a comparação das informações presentes nos apontamentos e nas fitas de vídeo. Além disso, os nomes desses arquivos precisam receber um símbolo que os diferencie dos arquivos com anotações das aulas que não foram gravadas. Efetuando uma busca por esse símbolo, é possível separar com apenas uma operação digital no próprio palmtop todos os arquivos que contenham anotações de aulas gravadas e não gravadas. Esse mesmo artifício pode ser utilizado para facilitar a posterior localização no interior dos apontamentos de informações específicas que precisem ser reunidas e sistematizadas para análise. Os símbolos utilizados nesse caso devem ser decorados pelo pesquisador para que seu uso não diminua a velocidade de elaboração dos apontamentos. Por via das dúvidas, vale a pena criar no palmtop um arquivo que funcione como um menu desses símbolos.

Para a realização dos apontamentos em campo, não é necessário utilizar um palmtop com editor de texto compatível com os existentes nos computadores pessoais. Basta a utilização de um handheld com um software de bloco de notas capaz de criar arquivos de texto sem formatação. A performance deste software é normalmente superior à dos emuladores de editor de texto existentes nos handhelds. A utilização dos emuladores não é recomendada nos handhelds, pois seus arquivos exigem muito espaço na memória do aparelho e seus recursos de formatação, desnecessários aos objetivos da pesquisa, tornam muito lentas as anotações do pesquisador.

Os apontamentos realizados num palmtop podem ser perdidos em função de quedas acidentais, do fim da carga das baterias ou de invasões por vírus - durante a conexão a um computador pessoal. Para que a informação contida em seus arquivos de texto não seja perdida, é necessário utilizar constantemente um software que realize a sincronia de dados entre o palmtop e um computador pessoal. Uma vez nele, os apontamentos podem ser salvos em cópias de segurança.

De acordo com Roger Sanjek (1990), as notas de campo propriamente ditas são realizadas a partir dos apontamentos, quando o pesquisador se retira do contexto. Anteriormente, Margaret Mead (1977) afirmou que isso deve ser feito oportunamente, antes que os apontamentos fiquem "frios". As notas de campo são resultado da complementação e do aprofundamento dos apontamentos a partir das lembranças do pesquisador. Segundo Sanjek (1990), as lembranças são registradas na memória do pesquisador independentemente de sua vontade e constituem as recordações dos fatos vivenciados em campo. As lembranças variam de acordo com a capacidade que o pesquisador tem para memorizar os acontecimentos e com as alterações sofridas pelas relações afetivas que ele estabelece com os atores de campo pesquisados. As lembranças são as notas de campo menos rigorosas e, ao mesmo tempo, podem ser aquelas que mais influenciam o pesquisador nas conclusões que tira de seu trabalho. 1sso ocorre porque as lembranças estão sempre submetidas aos preconceitos do pesquisador e porque é difícil controlar a influência desses preconceitos sobre elas. Para administrar os preconceitos arraigados em suas lembranças, é importante que o pesquisador resgate de relatórios de pesquisas 
anteriores os preconceitos já identificados em suas notas de campo. São exemplos de preconceitos comuns à pesquisa de observação de sala de aula a visão de escola do pesquisador como aluno e como professor, suas representações sobre seus professores preferidos, sua indignação diante de algumas posturas dos atores de campo, sua maior simpatia por perspectivas de ensino e posições ideológicas que são as suas próprias. É importante que o pesquisador elabore e utilize a lista de preconceitos que influenciam sua leitura do que ocorre em campo para reavaliar cada lembrança, refletindo sobre como esses preconceitos poderiam interferir em sua observação. Essa reflexão pode ocorrer sistematicamente em vários momentos da pesquisa, como durante 0 processo de transformação dos apontamentos em notas de campos propriamente ditas, durante 0 processo de hierarquização das asserções empíricas originadas das fontes de dados e durante a redação dos relatórios de pesquisa.

Fazem parte das lembranças não apenas as aulas observadas, mas também as situações experienciadas fora do contexto da aula e até mesmo fora do espaço da escola, nas quais às vezes não é possível realizar sequer apontamentos. Muitos diálogos estabelecidos com os atores de campo na sala dos professores, nos corredores da escola, na cantina, no bar ou no restaurante da esquina e no caminho de uma escola a outra fornecem informações importantes para o pesquisador. Além de informar o pesquisador, essas situações informais têm grande importância na obtenção da solidariedade e da camaradagem dos atores de campo, discutida anteriormente. Para evitar que todas essas situações menos formais - mas não menos importantes - fiquem submetidas apenas às suas lembranças, o pesquisador pode utilizar equipamentos que garantam algum registro delas. Um gravador de voz digital é pequeno o suficiente para ser carregado no bolso do pesquisador o tempo todo e assegurar o registro da fala dos atores de campo mesmo em situações inusitadas - sempre com o consentimento dos atores de campo. Uma pequena câmera foto- gráfica digital sempre em poder do pesquisador pode garantir o registro de alguma situação envolvendo os atores de campo, o registro de um texto escrito num cartaz que pode ser arrancado antes que o pesquisador tenha tempo para copiá-lo ou o registro de um trecho de livro que não poderá ser emprestado ao pesquisador. Um smartphone combina todos esses equipamentos portáteis num só: permite a realização dos apontamentos num bloco de notas digital, a gravação de voz em formato digital e a realização de fotos e vídeos.

Quando realizados num palmtop, os apontamentos elaborados num software de bloco de notas podem ser sincronizados com um computador pessoal, copiados para um arquivo de editor de texto e complementados para se transformarem em notas de campo. Além de facilitar sua redação, ao permitir que se complemente o que foi anotado, em vez de passar a limpo tudo o que já foi escrito, a realização dos apontamentos num palmtop permite também que o pesquisador leve facilmente todos eles de volta ao campo no dia seguinte.

Depois de elaboradas, as notas de campo podem ser transferidas do computador pessoal do pesquisador para seu palmtop. Assim, o pesquisador pode manter nele uma pasta com todos os arquivos de apontamentos e outra pasta com os arquivos de notas de campo. Em alguns casos, uma consulta a elas no contexto pesquisado auxilia na recuperação de algumas informações importantes para a realização dos apontamentos que nem sempre estão presentes nas lembranças do pesquisador.

Sempre que tem algum tempo no próprio campo para transformar seus apontamentos em notas, o pesquisador pode fazê-lo diretamente em seu palmtop e posteriormente salvá-las em seu computador pessoal. lsso pode ocorrer quando, por exemplo, é necessário permanecer na escola sem observar aulas em função da falta de um professor ou da dispensa dos alunos para a realização de outras atividades. Além disso, durante a análise dos dados coletados, os apontamentos e as notas de campo realizados num palmtop podem 
ser consultados diretamente no mesmo computador pessoal no qual o pesquisador redige seu relatório ou artigo. Isso facilita a manipulação dos dados, consultados sob a forma de janelas numa tela em vez de centenas de páginas distribuídas por diversos cadernos. Outra grande vantagem da posse dos apontamentos em formato digital é sua fácil reprodutibilidade, possibilitando a realização de diferentes tipos de exames de seu conjunto completo. 0 pesquisador pode salvar diferentes versões de um mesmo apontamento ou nota de campo para grifá-los, complementá-los e analisá-los de formas distintas.

A realização de apontamentos num palmtop reproduz um dos problemas da escrita em blocos de papel: escrever com uma caneta na mão, seja ela uma caneta-tinteiro ou um stylus, exige que o pesquisador desvie a atenção do que está sendo observado ou tome notas muito sintéticas. Uma forma de evitar esse problema é realizar os apontamentos num notebook, o que permite ao pesquisador digitar o que está pensando sem desviar seu olhar do que ocorre na sala de aula. Entretanto, isso exige que o pesquisador permaneça fixo num ponto da sala para fazer as anotações, sem poder acompanhar o professor pela sala. Um pesquisador que realize seus apontamentos num notebook precisa de outros equipamentos digitais, para compensar sua imobilidade, como microcâmeras que transmitam para seu notebook imagens de outros ângulos da sala que ele não consegue observar de onde está.

A facilidade de reprodução dos apontamentos em formato digital permite também que o pesquisador envie no mesmo dia seus apontamentos, notas de campo e reflexões sobre eles para outros membros de um mesmo grupo de pesquisa. Isso substitui com agilidade alguns dos papéis desempenhados pelas tradicionais "cartas, relatórios e artigos" - letters, reports and papers - elaborados em campo, criados para garantir que a interlocução de um pesquisador inserido num contexto com outros que estão fora dele possa aguçar sua observação sobre o que está ocorrendo (Sanjek, 1990). As diversas mensagens de correio eletrônico resultantes desse processo de comunicação, além de armazenadas no computador pessoal do pesquisador, podem ser levadas a campo em seu palmtop. As notas em campo em formato digital e as reflexões do pesquisador sobre elas podem ser enviadas ao mundo todo em alguns segundos, não se restringindo à cidade nem mesmo ao país do pesquisador.

\section{Vídeos digitais da sala de aula}

A utilização do palmtop para a elaboração dos apontamentos propiciou todas as vantagens já descritas, especialmente permitir ao pesquisador acompanhar o professor pela sala. Quando o pesquisador não pode se movimentar pela sala por algum motivo relacionado à dinâmica da aula, mas também não deseja deixar de observar os detalhes de seus acontecimentos, os apontamentos podem ser realizados num notebook que também receba o sinal de microcâmeras de vídeo.

Uma microcâmera pode ser estabelecida no alto da tela do notebook, captando o ponto de vista do pesquisador - um plano geral da sala vista do fundo e o som desse local. Outra microcâmera, sem fio, embutida nos óculos utilizados pelo professor observado, pode captar seu ponto de vista (Zouinar, s/d).

A microcâmera também pode ser colocada num avental, especialmente adaptado para esse fim, para captar as falas do professor observado e as imagens e falas dos alunos próximos a ele. A microcâmera sem fio precisa ficar posicionada num pequeno bolso criado no alto do avental. Ela pode ser alimentada por baterias recarregáveis colocadas em outro bolso e ligadas a ela por cabos que passam por dentro do avental.

As imagens transmitidas por essas duas câmeras podem ser observadas pelo pesquisador na tela do notebook, dividida com o editor de texto em que são realizados os apontamentos. Os sons transmitidos por essas duas câmeras podem ser monitorados pelo pesquisador por meio de um fone de ouvido ligado ao notebook.

Com esse recurso, além de acompanhar as falas do professor e observar as expressões 
e falas dos alunos próximos a ele, a distância e em tempo real, o pesquisador pode gravar essas sons e imagens para consulta futura, criando um novo tipo de fonte de dados. Para isso, devem ser utilizados circuitos que permitam editar e gravar essas imagens e sons no disco rígido do notebook e depois transferi-los para DVDs graváveis, onde ficarão armazenados.

As imagens e os sons captados pelas duas câmeras precisam ser injetados num circuito seletor de áudio e vídeo, por meio do qual o pesquisador escolhe durante a observação das aulas qual microfone e qual câmera terão seus sinais enviados para a gravação. Desse seletor, as imagens e os sons escolhidos podem ser enviados para um circuito de captura de vídeo analógico que os digitaliza e os transfere para o notebook, no qual são gravados como arquivos digitais. Para facilitar a montagem e desmontagem desses circuitos e sua transferência de uma sala de aula para outra, eles devem ser montados num recipiente que caiba na mochila do notebook.

As imagens de apenas uma das câmeras podem ser gravadas de cada vez, mas o pesquisador pode alterar a qualquer momento a câmera selecionada. Os sons dos dois microfones podem ser gravados ao mesmo tempo com a imagem selecionada. Dependendo do acontecimento observado, o pesquisador pode optar por gravar os sons captados pelos dois microfones ou apenas os sons captados pelo microfone melhor posicionado. Por exemplo, numa situação de trabalho em grupos, podem ser gravados apenas os sons captados pelo microfone presente nos óculos ou no avental do professor. Os sons captados pelo microfone estabelecido próximo ao pesquisador podem ser ignorados, pois captam apenas o ruído incompreensível de vários grupos trabalhando. Já numa aula expositiva em que ocorre um diálogo entre o professor observado e um aluno sentado no fundo da sala, mais próximo do pesquisador do que do professor, podem ser gravados os sons captados pelos dois microfones. lsso permite que as falas do aluno, e não apenas as do professor, sejam gravadas com qualidade.
Uma terceira câmera pode ser emprestada aos atores de campo para que eles gravem aulas que o pesquisador não pode observar por solicitação dos atores de campo ou por impedimento do próprio pesquisador. As imagens captadas por essa câmera, operada pelo próprio professor sem a presença do pesquisador, constituem mais uma fonte de dados. Essas imagens e sons também podem ser armazenadas pelo pesquisador em DVDs graváveis.

0 uso de gravações em vídeo das aulas observadas exige alguns cuidados, por parte do pesquisador, relativos aos problemas éticos envolvidos no uso desse equipamento. As microcâmeras são muito associadas a espionagem ou sistemas de segurança empresariais. Para utilizá-las num contexto de pesquisa, é preciso dissociá-las dessa imagem.

As aulas podem ser gravadas somente quando os atores de campo estão absolutamente seguros de que o pesquisador pode fazê-lo. Os atores de campo observados precisam ser informados de que, sempre que desejarem, poderão solicitar, sem qualquer justificativa, que o pesquisador não grave uma aula que esteja prestes a começar ou que apague uma aula já gravada. Os alunos precisam ser informados de que ninguém além do pesquisador verá essas imagens. Os diretores e coordenadores pedagógicos precisam ser informados de que somente podem ter acesso às gravações com a autorização dos professores observados e depois que eles as vejam.

A principal ameaça ao rigor de uma pesquisa interpretativa está relacionada à coleta de um volume inadequado de cenas portadoras de manifestações capazes de respaldar as principais asserções criadas pelo pesquisador (Erickson, 1985). No entanto, quando as aulas observadas também são registradas em vídeo, alguns de seus aspectos são revistos e reinterpretados pelo pesquisador mesmo depois de deixado o contexto de campo. Isso garante que informações não registradas nas notas de campo, por não chamarem a atenção do pesquisador naquele momento, sejam recuperadas posteriormente. 
Um exemplo dessa complementaridade entre notas de campo e gravações em vídeo, e de como isso pode evitar a coleta de um volume inadequado de cenas portadoras de manifestações capazes de respaldar as principais asserções, ocorreu numa pesquisa de campo realizada pelos autores. Durante a realização dos apontamentos de uma aula, o pesquisador percebeu que os alunos de uma escola privada referiam-se aos senhores de engenho na segunda pessoa, identificando-se com eles. Nesse momento, lembrou-se de que observara os alunos de outra escola em situação semelhante - numa escola estatal - e supôs que eles se referiam aos senhores de engenho na terceira pessoa. Entretanto, o pesquisador não tinha registrado essa informação em suas notas de campo, pois quando elas foram redigidas isso não the chamava a atenção. Revendo os vídeos das aulas, o pesquisador pôde retomar a fala dos alunos e confirmar que eles realmente se referiam aos senhores de engenho na terceira pessoa. A partir de então, criou a hipótese de que essa poderia ser uma diferença significativa entre o ensino de História numa escola estatal e numa escola privada e passou a observar com mais atenção tal ocorrência.

Outra ameaça ao rigor da pesquisa interpretativa, que a realização de gravações em vídeo ajuda a evitar, é a tendência ao direcionamento da observação e da amostra de dados. Essa tendência pode provocar o destaque dos tipos de acontecimento que ocorrem com maior frequência, pois são os que o pesquisador compreende mais completamente com o tempo. De acordo com Frederick Erickson (1985), dadas as limitações sobre o que se pode contemplar com maior atenção em cada experiência de observação, é possível que o pesquisador tenda a centrar-se, quase desde o princípio, em alguma teoria que está induzindo. Nesse caso, durante suas observações, prestará atenção sobre todos aqueles aspectos da ação que corroboram a teoria induzida, deixando de registrar outros aspectos que poderiam refutar essa teoria. Todavia, a realização de gravações em vídeo garante que os acon- tecimentos menos frequentes, que normalmente passam despercebidos durante a coleta de dados, sejam retomados posteriormente na análise das gravações. Isso reduz a dependência do pesquisador em relação aos acontecimentos de aparência reiterada como suas melhores fontes de dados, pois existe a possibilidade de estudar de maneira bastante completa os acontecimentos pouco frequentes, passando várias vezes a gravação correspondente.

Apesar de limitarem algumas das ameaças ao rigor da pesquisa interpretativa, as gravações podem implicar outras. Segundo Frederick Erickson (1985), ao assistir a uma gravação, o pesquisador não pode interferir no acontecimento gravado, não tendo a oportunidade de verificar as teorias que elabora mediante o recurso de pô-las à prova como participante ativo das cenas observadas.

Além disso, para entender os significados do material gravado, o pesquisador necessita de informações contextuais que não aparecem na própria gravação. Quando esse contexto tem muita influência sobre o desenvolvimento das relações sociais dentro da aula, a ausência de um marco contextual mais amplo pode invalidar a análise. Para evitar essas duas limitações do uso de gravações em vídeo como fontes de dados, é necessário combinar a observação participante com a análise das gravações.

\section{Concluindo: metodologia e tecnologia nas pesquisas de observação de sala de aula}

0 estranhamento do familiar, a conquista da "solidariedade" e da "camaradagem" dos atores de campo e o estabelecimento de uma certa diferença entre observação e interpretação são problemas enfrentados pelos observadores de sala de aula que podem ser minimizados pelo uso de tecnologia digital em campo. 0 uso dessa tecnologia, orientado por uma metodologia, não apenas agiliza ou facilita o ofício do pesquisador. 0 uso de palmtops, gravadores de áudio e câmeras fotográficas digitais, smartphones, microcâmeras sem fio, notebooks e editores de 
áudio e vídeo multiplica as possibilidades de criação de tipos de fonte de dados e auxilia os observadores de sala de aula a ampliar significativamente o rigor e a validade de seu trabalho.

Conforme afirmado anteriormente, o estranhamento do familiar não é necessariamente uma condição de êxito das pesquisas de observação de sala de aula, mas a utilização de equipamentos digitais nessas pesquisas pode contribuir para o estranhamento quando o pesquisador julgá-lo seja necessário em seu trabalho. 0 registro de múltiplos ângulos dos acontecimentos da aula e a possibilidade de rever infinitamente esses registros permite ao pesquisador estranhar algo que a familiaridade tornaria impossível de reflexão quando visto de um único ângulo ou apenas uma vez. No entanto, essa facilitação tecnológica não torna o estranhamento do familiar uma condição de êxito da pesquisa de observação de sala de aula, cuja metodologia define se o estranhamento é realmente necessário.

A conquista da "solidariedade" e da "camaradagem" dos atores de campo pode ser facilitada pelo uso de equipamentos digitais em campo porque eles permitem registrar informações mesmo nas situações mais informais, necessárias à criação de laços com os atores de campo. 0 uso de tecnologia digital em campo também permite aos atores a observação de gravações de seus discursos e de outras de suas práticas, tanto para ajudá-los a solucionar problemas cotidianos quanto para esboçar um sentido aos proble- mas insolúveis. Essa autoconfrontação dos atores de campo com os registros da pesquisa amplia seus laços com o pesquisador e auxilia na conquista da "solidariedade" e da "camaradagem" desses atores.

0 estabelecimento de certa diferença entre observação e interpretação também é facilitado pelo uso de equipamentos digitais, na medida em que eles permitem ao pesquisador registrar de múltiplas formas o que ele observa em campo. 0 uso dessa tecnologia permite uma observação mais refletida do que espontânea, focada também nos gestos, e não somente nos sentidos atribuídos a eles. As diversas possibilidades de retomada do material elaborado e coletado digitalmente pelo pesquisador em campo permite atribuir aos gestos um sentido diferente daquele que seria atribuído no calor do campo. 0 uso de equipamentos digitais permite ao pesquisador a possibilidade de evitar juízos de valor muito rígidos em campo, pois atribui um papel importante à reflexão efetuada fora dele e, com isso, busca separar observação de interpretação. Essa tecnologia não garante nenhuma objetividade à interpretação do pesquisador, mas otimiza sua responsabilidade de aproximar-se constantemente de seu objeto. Essa responsabilidade é necessária para evitar que a pesquisa de observação de sala de aula fique refém da autoridade do pesquisador e para permitir que essa pesquisa assuma como critérios de validade a apresentação de provas e a adequação de suas afirmações ao real. 


\section{Referências bibliográficas}

CALDEIRA, T. P. do R. A presença do autor e a pós-modernidade em antropologia. Novos Estudos, São Paulo, n. 21, p. 133-157, jul. 1988.

CARDOSO, 0. P. Representações dos professores sobre saber histórico escolar. 2003. 136 p. Dissertação (Mestrado)Faculdade de Educação, Universidade de São Paulo, 2003. Disponível em: <http://www.tudoehistoria.com.br/paginas/ mestrado.html>.

A Didática da História e o slogan da formação de cidadãos. 2007. 245 p. Tese (Doutorado) - Faculdade de Educação, Universidade de São Paulo, 2007. Disponível em: <http://www.tudoehistoria.com.br/paginas/doutorado.html>.

CHERVEL, A. História das disciplinas escolares: reflexões sobre um campo de pesquisa. Teoria \& Educação, Porto Alegre, n. 2, p. 117229, 1990.

La culture scolaire: une approche historique. Paris: Belin, 1998.

ERICKSON, F. Qualitative methods in research on teaching. In: WITTROCK, M. C. (Org.). Handbook of research on teaching. New York: Macmillan, 1985. p. 119-161.

FONSECA, C. Quando cada caso não é um caso: pesquisa etnográfica e educação. Revista Brasileira de Educação. Rio de Janeiro, n. 10, p. 58-78, 1999.

FOOTE-WHITE, W. Treinando a observação participante. In: GUIMARÃES, A. Z. (Org.). Desvendando máscaras sociais. Rio de Janeiro: Francisco Alves, 1980.

FREITAS, R. S. de; BATITUCCI, E. C. A falácia da interpretação da cultura como texto. Lua Nova, São Paulo, n. 40/41, p. 267-288, 1997.

GEERTZ, C. A interpretação das culturas. Rio de Janeiro: Jorge Zahar, 1978.

GINZBURG, C. Relações de força: história, retórica, prova. São Paulo: Companhia das Letras, 2002.

INWOOD, M. Dicionário Hegel. Rio de Janeiro: Jorge Zahar, 1997.

KOSIK, K. Dialética do concreto. Rio de Janeiro: Paz e Terra, 1976.

LEFEBVRE, H. La presencia y la ausencia: contribución a la teoría de las representaciones. México: Fondo de Cultura Económica, 1983.

MALINOWSKI, B. K. Argonautas do pacífico ocidental. São Paulo: Abril Cultural, 1984.

MEAD, M. Letters from the field: 1925-1975. New York: Harper \& Row, 1977.

PENIN, S. T. de S. A satisfação/insatisfação no trabalho e suas relações com as determinações objetivas da prática pedagógica desenvolvida pelo professor de primeira a quarta série da rede municipal de ensino de São Paulo. Dissertação (Mestrado)- Pontifícia Universidade Católica, São Paulo, 1980.

Cotidiano e escola: a obra em construção. São Paulo: Cortez, 1989.

A aula: espaço de conhecimento, lugar de cultura. Campinas: Papirus, 1994.

A professora e a construção do conhecimento sobre o ensino. Cadernos de Pesquisa. São Paulo, n. 92, p. 5-15, 1995.

RUSSELL HANSON, N. Observação e interpretação. In: MORGENBESSER, S. (Org.). Filosofia da ciência. São Paulo: Cultrix, 1975.

SANJEK, R. Fieldnotes: the makings of anthropology. Ithaca: Cornell University Press, 1990.

SCHNEIDER, M. A. Culture as a text? In: Culture and enchantment. Chicago: University of Chicago Press, 1993. 
STOCKING, G. W. The ethnographer's magic: fieldwork in British anthropology from Tylor to Malinowski. In: (Org.).

Observers observed: essays on ethnographic fieldwork. Madison: The University of Wisconsin Press, 1983, p. 70-120.

THOMSON, A. et al. Os debates sobre memória e história: alguns aspectos internacionais. In: AMADO, J.; FERREIRA, M. de M. Usos e abusos da história oral. Rio de Janeiro: Fundação Getúlio Vargas, 1996.

WILLIS, P. Aprendendo a ser trabalhador: escola, resistência e reprodução social. Porto Alegre: Artes Médicas, 1991.

ZOUINAR, M. Observation et capture de données sur l'interaction multimodale en mobilité. IRIT: Institut de Recherche en Informatique de Toulouse, s/d. Disponível em: <http://www.irit.fr/ Pascal.Salembier/PDF/ubiquite.pdf>.

Recebido em 18.12.07

Aprovado em 23.11.08

Oldimar Cardoso, doutor em Educação pela Universidade de São Paulo, é pós-doutorando em História pela Universidade de Augsburg (Alemanha) e pela Universidade de São Paulo.

Sonia Teresinha de Sousa Penin é professora titular e diretora da Faculdade de Educação da Universidade de São Paulo. 